\title{
Ongoing outbreak of visceral leishmaniasis in Bologna Province, Italy, November 2012 to May 2013
}

S Varani (stefania.varani@unibo.it) ${ }^{1}, \mathrm{R}$ Cagarelli ${ }^{2}$, F Melchionda 3 , L Attard ${ }^{4}$, C Salvadori ${ }^{4}$, A C Finarelli ${ }^{2}$, G A Gentilomi ${ }^{1}$, R Tigani ${ }^{1}$,

R Rangoni ${ }^{5}$, R Todeschini ${ }^{6}$, A Scalone ${ }^{7}$, T Di Muccio ${ }^{7}$, M Gramiccia ${ }^{7}$, L Gradoni ${ }^{7}$, P Viale ${ }^{4}$, M P Landini $^{1}$

1. Unit of Microbiology, Regional Reference Center for Microbiological Emergencies (CRREM), St. Orsola Malpighi Hospital, University of Bologna, Bologna, Italy

2. Public Health Authority Emilia-Romagna, Bologna, Italy

3. Department of Pediatric Hematology and Oncology, St. Orsola Malpighi University Hospital, Bologna, Italy

4. Infectious Disease Unit, St. Orsola Malpighi Hospital, University of Bologna, Italy

5. Public Health Department of Imola, Bologna, Italy

6. Public Health Department of Casalecchio di Reno, Bologna, Italy

7. Unit of Vector-Borne Diseases and International Health, Istituto Superiore di Sanità, Rome, Italy

Citation style for this article:

Varani S, Cagarelli R, Melchionda F, Attard L, Salvadori C, Finarelli AC, Gentilomi GA, Tigani R, Rangoni R, Todeschini R, Scalone A, Di Muccio T, Gramiccia M, Gradoni L, Viale P, Landini MP. Ongoing outbreak of visceral leishmaniasis in Bologna Province, Italy, November 2012 to May 2013. Euro Surveill.

2013;18(29): pii=20530. Available online: http://www.eurosurveillance.org/ViewArticle.aspx?Articleld=20530

An increased number of autochthonous visceral leishmaniasis (VL) cases has recently been reported in Bologna Province in northern Italy. Over six months from November 2012 to May 2013, 14 cases occurred, whereas the average number of cases per year was 2.6 (range: $0-8$ ) in 2008 to 2012. VL was diagnosed in a median of 40 days (range: 15-120) from disease onset. This delay in diagnosis shows the need for heightened awareness of clinicians for autochthonous VL in Europe.

From November 2012 to May 2013, public health authorities, microbiologists and clinicians in Bologna Province, northern Italy, noted an upsurge in human cases of visceral leishmaniasis. During these six months, 14 cases were notified, an over five-fold increase compared with the annual average of 2.6 cases (range: 0-8) from 2008 to 2012. Here, we report preliminary epidemiological, microbiological and clinical findings.

\section{Background}

Visceral leishmaniasis (VL) is a severe disease primarily affecting the host's reticuloendothelial system and is caused by parasitic protozoans belonging to the Leishmania donovani complex. VL is endemic in Mediterranean Europe, where the disease is caused by L. infantum. Transmission is mainly zoonotic and occurs via the bite of a phlebotomine sandfly species of the genus Phlebotomus $[1,2]$. In Italy, the Tyrrhenian littoral, the southern peninsular regions and the islands have been considered classical endemic zones for VL, whereas in continental northern regions, VL has mainly affected human immunodeficiency virus (HIV)-positive patients. Since the early 1990s, however, a northward spread of the disease to previously non-endemic Italian regions has been observed. These regions also exhibited a progressive decrease in HIV co-infection rates [3]. A recent survey conducted in a continental area of north-western Italy, which was previously considered to be non-endemic, detected anti-leishmanial antibodies in $7.4 \%$ of healthy adults; for half of the seropositives, ongoing infection was confirmed by PCR analysis [4]. Currently, the occurrence of both asymptomatic and symptomatic leishmaniasis seems to be underestimated in Italy.

\section{Outbreak description}

In Italy, laboratory-confirmed cases of VL are reported by local public health departments to the regional authorities, which report cases to the Ministry of Health. The case definition for VL in Italy is based on the World Health Organization (WHO) case definition

\section{FIGURE 1}

Epidemic curve of human cases of visceral leishmaniasis, Bologna Province, northern Italy, November 2012-May $2013(n=14)$

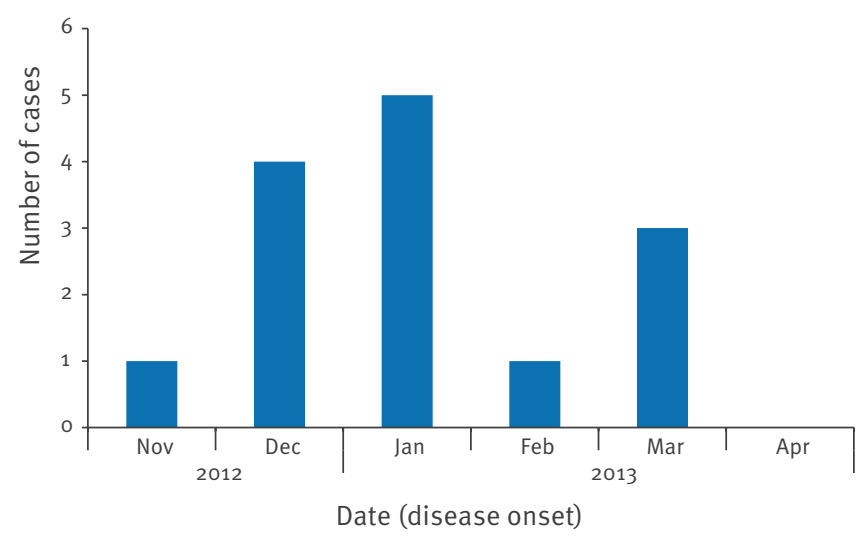




\section{FIGURE 2}

Geographical location of human cases of visceral leishmaniasis, Bologna Province, northern Italy, November 2012-May 2013 (n=14)

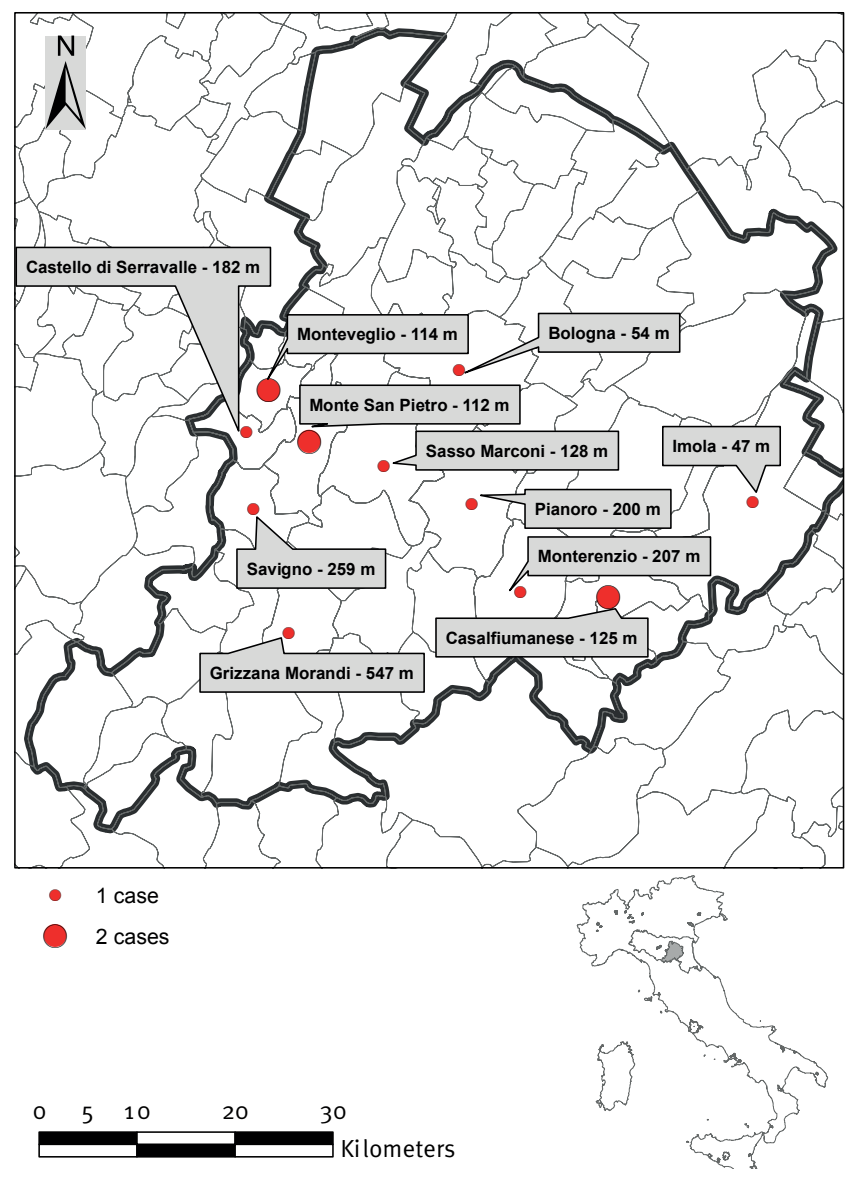

m: meters above sea level

and includes positive serology (indirect immunofluorescence antibody test (IFAT), ELISA, rK39-based immunochromatographic test (IC), direct agglutination test) and/or parasitology (microscopy, culture or PCR) for patients with suspected clinical symptoms [5].

From November 2012 to May 2013, 14 new cases of VL occurred in Bologna Province in northern Italy (Figure 1). Most patients resided in hilly, rural areas. Municipalities and their altitudes are reported in Figure 2.

The age range of patients was five months to 83 years, four cases were aged 18 months or younger, five were between 48 and 60 years-old, and five were between 62 and 83 years-old. The majority, 11 patients, were male. One patient was HIV-positive. Overall, five patients had known risk factors for VL, i.e. being under two years-old, $(n=4)$ or being HIV-positive $(n=1)$. All patients had symptoms compatible with VL, including a fever of unknown origin $(n=13)$, mild to moderate anaemia $(n=12)$, leukopenia $(n=12)$, thrombocytopenia $(n=10)$, hepatomegaly $(n=7)$, splenomegaly $(n=14)$ and weight loss $(n=7)$. Interestingly, four of $14 \mathrm{VL}$ cases presented with haemophagocytic syndrome (HS), a systemic hyperinflammatory disorder with severe dysfunction of immune homeostasis that may be secondary to VL $[6,7]$.

VL was diagnosed in a median time of 40 days from disease onset (range: 15-120) and was supported by parasitological and serological means.

\section{Laboratory investigations}

Bone marrow aspirate was performed in 12 cases, but smear was available for microscopic diagnosis only in 10 cases. The detection of amastigotes was positive in three of 10 cases investigated, and the culture was negative in all nine tested cases (Table), suggesting a low parasite load in the bone marrow [8]. As expected [9], molecular methods enhanced parasite detection in bone marrow samples. Leishmanial DNA was detected by nested PCR and/or real-time PCR in seven of 10 patients and in the peripheral blood of an additional patient who was HIV-positive; thus, molecular methods were positive in eight of $13 \mathrm{VL}$ cases (not performed in one case).

Serology performed using an indirect haemagglutination assay (IHAT) was negative in all eight cases tested, whereas the rk39-based IC [10] and IFAT were positive in all tested patients ( 10 of 10 and 13 of 13 , respectively, see Table). Thus, serodiagnosis by IFAT or IC in patients with suspected symptoms was fundamental.

Indeed, in four of five cases in whom a diagnosis of VL was posited based on only suggestive symptoms and serological tests, the response to anti-leishmanial treatment (liposomal amphotericin B, $10 \mathrm{mg} / \mathrm{kg}$ intravenous, single dose) was appropriate, suggesting that our diagnostic approach was correct. One case resolved symptoms without treatment and is currently under clinical and laboratory evaluation.

\section{Discussion}

The risk of the emergence or resurgence of several exotic vector-borne pathogens in Europe, including chikungunya and dengue virus, has become a hot topic over the past decade, whereas other infections, such as leishmaniasis, have been neglected [11]. In fact, clinicians and microbiologists are often ill informed on the prevalence and symptoms of, and detection methods for VL, which may lead to initial misdiagnosis and a delay in diagnosis and treatment.

According to the epidemic curve (Figure 1), most cases of the ongoing outbreak in Bologna Province had disease onset in the winter months, indicating that patients were probably infected during summer and autumn 2012. Furthermore, half of the cases were diagnosed more than 40 days from disease onset and one of these cases was diagnosed 120 days after initial symptoms. This indicates a frequent delay in identifying the 
Parasitological and serological findings in visceral leishmaniasis cases, Bologna Province, Italy, November 2012-May 2013 $(\mathrm{n}=14)$

\begin{tabular}{|c|c|c|c|}
\hline Case number & Time to diagnosis & Parasitological findings & Serological findings \\
\hline 1 & 78 days & BM: microscopy - , PCR+ & IHAT-, IC+, IFAT+ (1:80) \\
\hline 2 & 27 days & BM: microscopy-, culture-, PCR+ & IHAT-, IC+, IFAT+ (1:160) \\
\hline 3 & 15 days & BM: microscopy -, culture-, PCR- & IHAT-, IC+, IFAT+ (1:160) \\
\hline 4 & 42 days & BM: microscopy - , culture-,PCR- & IC+, IFAT+ (1:40) \\
\hline 5 & 40 days & BM: microscopy+, culture-, PCR+ & IHAT-, IFAT+ (1:80) \\
\hline 6 & 15 days & BM: microscopy -culture-, PCR- & IC+, IFAT+ $(1: 1,280)$ \\
\hline 7 & 80 days & BM: microscopy -, culture-, PCR- & IHAT-, IC+, IFAT+ $(1: 5,120)$ \\
\hline 8 & 40 days & PB: PCR+ & IHAT-, IC+, IFAT+ $(1: 10,240)$ \\
\hline 9 & 120 days & PB: culture-, PCR- & IHAT-, IC+, IFAT+ $(1: 5,120)$ \\
\hline 10 & 20 days & BM: PCR+ & IHAT- \\
\hline 11 & 30 days & BM: microscopy + & IFAT+ (1:320) \\
\hline 12 & 25 days & BM: microscopy - , PCR+ & IFAT+ $(1: 1,280)$ \\
\hline 13 & 60 days & BM: microscopy+, culture-, PCR+ & IC+, IFAT+ (1:320) \\
\hline 14 & 50 days & BM: culture- , PCR+ & IC+, IFAT+ (1:640) \\
\hline
\end{tabular}

BM: bone marrow; PB: peripheral blood; IFAT: indirect immunofluorescence antibody test; IHAT: indirect haemagglutination test; IC: rk39based immunochromatographic test; -: negative; +: positive.

parasitic infection. One third of the identified cases were revealed as having HS, and one child was erroneously diagnosed as having familial haemophagocytic lymphohistiocytosis (FHL). Symptoms for FHL and HS due to VL may overlap, and the differential diagnosis can be difficult $[7,12]$. Thus, awareness of the increasing incidence of $\mathrm{VL}$ in areas previously considered to be at low risk is fundamental to avoid misdiagnosis, especially in infants in whom HS might be confused with FHL.

L. infantum is considered to be autochthonous in Bologna Province and $P$. perfiliewi is the predominant vector in this area [13]. In 1971-72, an outbreak of VL occurred in Bologna Province that affected 60 individuals, with 13 deaths [14]. Afterwards, the area remained endemic, with a low prevalence and an annual mean of 2.6 reported cases (range: $0-8$ years) for the years 2008 to 2012 (R. Cagarelli, personal communication, May 2013). The reasons for the recent upsurge of VL cases in Bologna Province are unknown. Theoretically, current global warming in the Mediterranean area [15] may enhance leishmaniasis distribution due to the effect of temperature on parasite development and vector spread. However, according to $\mathrm{WHO}$, there is no clear evidence indicating that sandfly and VL distribution in Europe have changed in response to climate change [2].

In conclusion, the increase in human VL cases in an area of northern Italy raises important public health concerns. Firstly, there is an urgent need to expand the existing control measures for canine leishmaniasis [13]. Secondly, healthcare professionals need to be informed of the upsurge in VL in the area to proceed with appropriate parasitological and serological tests in suspected cases, to promptly identify and treat cases of VL. Finally, the public needs to be aware of the potential exposure to sandfly bites in areas in which the parasite circulates, and to be educated in the use of appropriate preventive measures, such as mechanical and chemical repellents.

\section{Acknowledgements}

This study was supported by the Emilia-Romagna Region (Laboratory $\mathrm{P}_{3}$ funds) and by the University of Bologna (RFO funds).

\section{Conflict of interest}

None declared.

\section{Authors' contributions}

Designed the study: SV and MPL. Wrote the first draft: SV. Collected, synthesised and analysed the data: RC, ACF, LA, CS, FM, MG, AS, TDM, RT, GAG, RR and RT. Interpreted the results critically and revised the article to ensure important intellectual content: PV, LG and MPL. All authors read and approved the final manuscript. 


\section{References}

1. Gramiccia M, Gradoni L. The current status of zoonotic leishmaniases and approaches to disease control. Int J Parasitol. 2005;35(11-12):1169-80. http://dx.doi.org/10.1016/j. ijpara.2005.07.001. PMid:16162348.

2. Ready PD. Leishmaniasis emergence in Europe. Euro Surveill. 2010;15(10):pii=19505. Available from: http://www. eurosurveillance.org/ViewArticle.aspx?Articleld=19505. PMid:20403308.

3. Maroli M, Rossi L, Baldelli R, Capelli G, Ferroglio E, Genchi C, et al. The northward spread of leishmaniasis in Italy: evidence from retrospective and ongoing studies on the canine reservoir and phlebotomine vectors. Trop Med Int Health. 2008;13(2):256-64. http://dx.doi.org/10.1111/j.13653156.2007.01998.x. PMid:18304273.

4. Biglino A, Bolla C, Concialdi E, Trisciuoglio A, Romano A, Ferroglio E. Asymptomatic Leishmania infantum infection in an area of northwestern Italy (Piedmont region) where such infections are traditionally nonendemic. J Clin Microbiol. 2010;48(1):131-6. http://dx.doi.org/10.1128/JCM.00416-09. PMid:19923480. PMCid:PMC2812267.

5. World health Organization (WHO). Control of the leishmaniases. In: WHO Technical Report Series. Geneva: WHO; 2010. p. 175-6. Available from: http://whqlibdoc.who.int/trs/ WHO_TRS 949_eng.pdf

6. Henter II, Horne A, Arico M, Egeler RM, Filipovich AH, Imashuku $\mathrm{S}$, et al. HLH-2004: Diagnostic and therapeutic guidelines for hemophagocytic lymphohistiocytosis. Pediatr Blood Cancer. 2007;48(2):124-31. http://dx.doi.org/10.1002/pbc.21039. PMid:16937360.

7. Rajagopala S, Dutta U, Chandra KS, Bhatia P, Varma N, Kochhar R. Visceral leishmaniasis associated hemophagocytic lymphohistiocytosis--case report and systematic review. J Infect. 2008;56(5):381-8. http://dx.doi.org/10.1016/j. jinf.2008.02.013. PMid:18405976.

8. Chappuis F, Sundar S, Hailu A, Ghalib H, Rijal S, Peeling RW, et al. Visceral leishmaniasis: what are the needs for diagnosis, treatment and control? Nat Rev Microbiol. 2007;5(11):873-82. http://dx.doi.org/10.1038/nrmicro1748. PMid:17938629.

9. Antinori S, Calattini S, Longhi E, Bestetti G, Piolini R, Magni $C$, et al. Clinical use of polymerase chain reaction performed on peripheral blood and bone marrow samples for the diagnosis and monitoring of visceral leishmaniasis in HIVinfected and HIV-uninfected patients: a single-center, 8-year experience in Italy and review of the literature. Clin Infect Dis. 2007;44(12):1602-10. http://dx.doi.org/10.1086/518167. PMid:17516404.

10. Brandonisio O, Fumarola L, Maggi P, Cavaliere R, Spinelli R, Pastore G. Evaluation of a rapid immunochromatographic test for serodiagnosis of visceral leishmaniasis. Eur J Clin Microbiol Infect Dis. 2002;21(6):461-4. http://dx.doi.org/10.1007/s10096002-0739-8. PMid:12111603.

11. Dujardin JC, Campino L, Canavate C, Dedet JP, Gradoni L, Soteriadou K, et al. Spread of vector-borne diseases and neglect of Leishmaniasis, Europe. Emerg Infect Dis. 2008;14(7):1013-8. http://dx.doi.org/10.3201/eid1407.071589. PMid:18598618. PMCid:PMC2600355.

12. Singh G, Shabani-Rad MT, Vanderkooi OG, Vayalumkal JV, Kuhn SM, Guilcher GM, et al. Leishmania in HLH: a rare finding with significant treatment implications. J Pediatr Hematol Oncol. 2013;35(3):e127-9. http://dx.doi.org/10.1097/ MPH.obo13e318286d619. PMid:23511497

13. Baldelli R, Piva S, Salvatore D, Parigi M, Melloni O, Tamba $M$, et al. Canine leishmaniasis surveillance in a northern Italy kennel. Vet Parasitol. 2011;179(1-3):57-61. http://dx.doi. org/10.1016/j.vetpar.2011.01.052. PMid:21349642.

14. Pampiglione S, La Placa M, Schlick G. Studies on mediterranean Leishmaniasis. I. An outbreak of visceral leishmaniasis in Northern Italy. Trans R Soc Trop Med Hyg. 1974;68(5):349-59. http://dx.doi. org/10.1016/0035-9203(74)90148-5

15. Voiland A. 2009: Second warmest year on record; end of warmest decade. Washington: National Aeronautics and Space Administration (NASA); Jan 2010. Available from: http:// climate.nasa.gov/news/249 